\title{
Percutaneous Implantation of Valvular Aortic Bioprosthesis: Reconciling the Clinical and Economic Values of an Established Treatment
}

\author{
Dimytri Alexandre Siqueira ${ }^{1}$, Alexandre A. C. Abizaid ${ }^{2}$, Susheel Kodali³, Martin B. Leon ${ }^{4}$
}

0 ver the past decades, major advances have been made in the percutaneous treatment of structural heart diseases. Among the procedures used for this purpose, the transcatheter aortic valve implantation (TAVI; also known as transcatheter aortic valve replacement [TAVR]) has a prominent role, due to its proved effectiveness in promoting symptomatic benefits and reducing the mortality of elderly patients with aortic stenosis and unable to surgery, ${ }^{1}$ who are frequently attended to in clinical practice and who formerly had no alternative therapy for a disease with mortality rates of up to $75 \%$ after three years, or $2 \%$ per month. ${ }^{2}$ Driven by the continuous accumulation of evidence (from large registries s $^{3,4}$ and randomized trials), ${ }^{1,5}$ by the rapid development in tools, and by the vast technical experience, TAVR was adopted worldwide, and its indication is already established in Brazilian and international guidelines. ${ }^{6,7}$ Currently, it is recommended that TAVR should be the treatment of choice for patients with severe aortic stenosis deemed inoperable (class I, level of evidence B), being an alternative strategy for surgical aortic valve replacement (SAVR) in those patients at high surgical risk (class Ila, level of evidence B).

\section{See page 213}

Since the first implant, in $2002,{ }^{8}$ it is estimated that over 90,000 patients have undergone TAVR worldwide. Currently, two types of prostheses implanted via femoral access are available in Brazil (Sapien $\mathrm{XT}^{\circledR}$, Edwards Life sciences; and CoreValve ${ }^{\circledR}$, Medtronic Inc.), and it is estimated that approximately 700 patients have been treated with this technique in that country. Obviously, this number is well below the potential universe of patients referred for TAVR, if considering that: (1) currently Brazil has over 9 million people above the age of 70 years; ${ }^{9}(2)$ a recently published trial demonstrated that the prevalence of severe aortic stenosis is $3.4 \%$ in this age group, and approximately $40 \%$ of these patients are not candidates for surgery; from this universe of individuals without surgical possibility, approximately $40 \%$ would be indicated for TAVR. ${ }^{10}$ In this scenario, there would be over 45,000 patients who potentially would benefit from TAVR in Brazil. The lack of reimbursement for TAVR by public and supplemental health systems is one of the main reasons for the lack of a wider adoption of this procedure in that country.

Due to the increasing health expenditures observed globally, it is essential to carefully assess the effectiveness and costs of new technologies, aiming to promote a proper allocation of limited and finite resources. In the context of interventional cardiology, few of those effective diagnostic and therapeutic innovations introduced in daily practice are initially of low cost. The question could not be different with TAVR; it is therefore relevant to discuss the cost-effectiveness of this new procedure, since, as stated, there is no other treatment option capable of changing the inexorable course of the disease for many patients.

\footnotetext{
${ }^{1}$ Interventionist Cardiologist Physician at the Heart Structural Diseases of Coração do Instituto Dante Pazzanese de Cardiologia. São Paulo, SP, Brazil.

2 Director of the Invasive Cardiology Service of Instituto Dante Pazzanese de Cardiologia. São Paulo, SP, Brasil. São Paulo, SP, Brazil.

${ }^{3}$ Columbia University Medical Center/New York-Presbyterian Hospital and the Cardiovascular Research Foundation. New York, USA.
}

${ }^{4}$ Columbia University Medical Center/New York-Presbyterian Hospital
and the Cardiovascular Research Foundation. New York, USA.
Correspondence to: Dimytri Alexandre Siqueira. Setor de Cardiologia
Invasiva - Av. Dr. Dante Pazzanese, 500, prédio III, 1ํ andar - Ibira-
puera - São Paulo, SP, Brazil - CEP 04012909
E-mail: dimytrisiqueira@dantepazzanese.org.br

Received on: 9/1/ 2013 • Accepted on: 9/ 9/ 2013 


\section{TAVR is a treatment of great clinical value}

Several trials have demonstrated the effectiveness of TAVR, with high success rates; the mortality rate has been significantly lower than the surgical mortality predicted by risk scores (EuroSCORE and STSPROM)., ${ }^{1,-5}$ The procedure is effective in relieving stenosis, with sharp reduction of the transvalvar gradient and with achievement of valve areas comparable with, if not greater than, those observed after SAVR. The longer-term follow-up suggests that this acute result persists for at least five years. ${ }^{11}$ One of the most rewarding aspects of TAVR is the dramatic improvement in symptoms and quality of life after treatment, which has been demonstrated in all trials. Complications associated with the procedure, such as stroke, vascular events, and bleeding are worrisome, but the frequency of these events has decreased with the use of new devices and increased experience. $^{12}$

In the first randomized clinical trial on this treatment, the Placement of AoRTic TraNscathetER Valves (PARTNER) cohort B1, 358 elderly patients (mean age: 83 years) with severe symptomatic aortic stenosis $(93 \%$ of patients in New York Heart Association [NYHA] functional class III or IV) and with prohibitive surgical risk, were randomized to TAVR with the Edwards SAPIEN ${ }^{\circledR}$ prosthesis or to optimal medical treatment, which often included aortic balloon valvuloplasty. In fact, the patients included are representative of real-world practice, with multiple comorbidities and adverse prognosis. After 12 months, a significant reduction in mortality with TAVR was observed, compared with medical therapy $(30.7 \%$ vs. $50.7 \%, \mathrm{P}<0.001$ ); this benefit was consistent across all subgroups analyzed, with a number needed to treat (NNT) of 5 for one-year mortality. The life expectancy of patients undergoing the procedure increased from 1.2 to 3.1 years; lowest rate of new hospitalizations and significant improvement in left ventricular dysfunction constituted other benefits arising from the implantation of the prosthesis. By combining the outcomes of quality of life (QOL) with survival data - defining staying alive as a favorable evolution and with an increase of 10 points in a specific questionnaire for patients with heart failure (Kansas City Cardiomyopathy Questionnaire) $-48 \%$ of patients treated with TAVR and $14 \%$ of clinically treated patients experienced a satisfactory outcome. ${ }^{13}$ Notably, approximately $25 \%$ of patients undergoing TAVR achieved excellent evolution, and were classified as NYHA functional class I after 12 months. In a further analysis, it was demonstrated that the benefits observed in terms of survival, hospitalizations, and symptoms were maintained after two years of evolution. ${ }^{14}$

Other registries, such as SOURCE XT (consisting of 1,694 patients treated with Sapien $\mathrm{XT}^{\circledR}$ prosthesis by femoral route) and ADVANCE (1,015 patients who underwent implantation of the CoreValve ${ }^{\circledR}$ prosthesis), indicators of real world outcomes, confirmed the excellent results of randomized trials, with success rates of up to $95 \%$, and with survival rates after 30 days between $87 \%$ and $95.7 \%$.

\section{Would TAVR be a treatment of appropriate economic value?}

Economic analyses in health care are based on comparisons between new therapy with current treatments, assessing not only the costs, but also the differences in clinical efficacy. Although there are other possibilities, such assessments are needed when the new treatment in question is more effective, but has higher cost. The main types of economic evaluation are: cost-effectiveness and cost-utility. ${ }^{15}$

Cost-effectiveness is the most common form of economic analysis in health, and reveals the balance between the benefits and costs of a new treatment or a new approach. In general, cost-effectiveness analysis is measured in increased cost per unit of effectiveness (e.g., years of life saved) or by the incremental costeffectiveness ratio (ICER). Conversely, the analysis of cost-utility assesses not only the ultimate goal of treatment (survival), as well as its influence in the quality of life of the patient (e.g., symptoms), and is expressed in quality-adjusted life years (QALY). ${ }^{16}$

Several studies have been published on the costeffectiveness of TAVR versus medical therapy in patients deemed inoperable. The biggest study was based on individual data from each of the patients included in the PARTNER B cohort trial. Estimating the total cost of the procedure at US\$79,000 (including hospitalization, physicians' fees, and the cost of the prosthesis of US\$ 35,000), TAVR resulted in an ICER of US\$ 50,212, with QALY of US\$ 62,000. ${ }^{13}$

Recently introduced, the Brecker economic trial used data from 12 months' survival of patients treated with CoreValve ${ }^{\circledR}$ system and included in the ADVANCE registry, comparing them to the medical treatment group of the PARTNER B trial. ${ }^{17}$ Considering the health values practiced in the United Kingdom, the cost per QALY with the CoreValve ${ }^{\circledR}$ prosthesis was $£ 11,265$. Other analyses also based on the overall results of PARTNER cohort B trial, used Markov statistical models. A Canadian analysis by Doble et al. demonstrated an ICER of CAD 36,458 per additional year of life and CAD 51,324 per QALY. ${ }^{18}$ Analyzing the context of the United Kingdom, Watt et al. estimated $£ 16,100$ per QALY, in a time-horizon of ten years. ${ }^{19}$ Despite some differences in the methodology and estimated economic costs of the procedure, the results of these trials suggest that TAVR is an economically acceptable treatment for inoperable patients, determining an incremental cost that is similar to other medical treatments already implemented, 
such as implantable cardioverter-defibrillators, lung transplantation, and haemodialysis.

However, it could be argued that such results in international scenarios are not applicable to the Brazilian situation, especially because of differences regarding expenditures, in the health sector, among different countries. In the present issue of Revista Brasileira de Cardiologia Invasiva, Queiroga et al. ${ }^{20}$ evaluate, in a detailed study from the perspective of the private healthcare system, the ICER of TAVR in Brazil. Using estimates of the direct medical costs of the procedure (regarding hospital admission, the procedure itself, and administered medications) and the predictive statistical model based on the results of the PARTNER B trial, the authors performed an economic analysis of TAVR on the national scene. Taking as reference $\mathrm{R} \$ 65,000.00$ as the prosthesis value, the authors reported that the total cost of treatment with TAVR after five years was $R \$ 123,019.76$; of this total, R\$ 35,815.12 were spent with the conservative strategy. Estimating an improved survival with TAVR compared with the clinical treatment, the ICER was $R \$ 90,161.29$ in five years and $R \$$ $55,130.84$ in a time-horizon of ten years.

Based on these values of cost-effectiveness, are there conditions to finance them? From the public health standpoint, some countries (United States, Canada and England, for instance) set acceptable thresholds for cost-effectiveness ratios, considering new treatments or devices. For example, trials conducted in the United States define as a favorable threshold US\$ 50,000 per QALY; in Canada, such value is between 20,000 and 40,000 Canadian dollars. In England, the threshold is estimated at $£ 40,000$. In Brazil, the World Health Organization suggests as a threshold a value of up to three times the gross domestic product (GDP) per capita, or approximately $\mathrm{R} \$ 78,239.00$ in 2012. However and as previously emphasized in this article, the Brazilian Ministry of Health established an even greater limit for ICER, of US\$ 50,000. In the trial in question, the ICER for TAVR is situated below that threshold. Unfortunately, the extrapolation of these relationships to the area of private healthcare is controversial.

Some limitations of this article should be highlighted. First, the clinical benefits obtained by TAVR were considered constant during the time-horizon of five to ten years, although published data from clinical trials have follow-up periods of only two years. In these and other trials, the rates of long-term mortality are consistent with the age group and associated comorbidities (pulmonary, renal, and neurological diseases, as well as neoplasias), and approximately half of the deaths during the follow-up had, in many studies, noncardiac etiology. Therefore, considering an elderly population with major illnesses associated, it is concluded that the clinical benefits of the intervention decrease with time. In the PARTNER B trial, the prosthesis used was of an earlier generation (Edwards SAPIEN ${ }^{\circledR}$ ) in comparison to that used in Brazil, and was associated with a higher incidence of bleeding and vascular complications which can increase mortality and raise the costs of hospitalization. Another aspect to be discussed is the estimation of aortic valvuloplasty utilization, performed on the group of patients who received clinical treatment; in recent years, an increase in the indication for this procedure has been observed, aiming to promote symptomatic benefit to individuals for whom the implant of prosthesis is not possible for various reasons, including lack of reimbursement. The inclusion of the costs of aortic valvuloplasty in the group of patients kept under strict medical treatment could result in even lower values of ICER in the economic model adopted. Finally, it should be noted that the conclusions of the article of Queiroga et al. ${ }^{20}$ are based on the results of inoperable patients undergoing TAVR, and should not be extrapolated to patients with high surgical risk (assessed in the PARTNER A trial, with specific analysis of cost-effectiveness). ${ }^{21}$

Ultimately, the challenge remains: how assure to the patients the high clinical value effectiveness of TAVR reconciling them to their high cost economic in Brazil? In this sense, it is important to seek strategies to improve the ICER of TAVR that involve not only the reduction of the cost of the prosthesis. Other recommended measures include compliance with the technical aspects of the procedure; prevention of complications; earlier mobilization of patients, reducing the length of hospital stay; and avoidance of unnecessary additional tests to monitor these individuals. Fundamentally, patients to be submitted to TAVR must be properly selected: those who can not only overcome its risks, but really enjoy the long term benefits of this new, efficient, and already established treatment.

\section{CONFLICTS OF INTEREST}

S. Kodali and M. Leon are consultants of Edwards Lifesciences. The other authors declare to have no conflicts of interest.

\section{REFERENCES}

1. Leon MB, Smith CR, Mack M, Miller DC, Moses JW, Svensson LG, et al.; PARTNER Trial Investigators. Transcatheter aortic-valve implantation for aortic stenosis in patients who cannot undergo surgery. N Engl J Med. 2010;363(17):1597-607.

2. Ross J Jr, Braunwald E. Aortic stenosis. Circulation. 1968; 38(1 Suppl):61-7.

3. Thomas M, Schymik G, Walther T, Himbert D, Lefevre T, Treede H, et al. One-year outcomes of cohort 1 in the Edwards SAPIEN Aortic Bioprosthesis European Outcome (SOURCE) registry: the European registry of transcatheter aortic valve implantation using the Edwards SAPIEN valve. Circulation.2011;124(4):425-33.

4. ADVANCE: TAVI Mortality with Corevalve Still Falling. In: Medscape [Internet]. [cited 2013 Oct 07]. Available from http://www.medscape.com/viewarticle/773203 
5. Smith CR, Leon MB, Mack MJ, Miller DC, Moses JW, Svensson LG, et al.; PARTNER Trial Investigators. Transcatheter versus surgical aortic-valve replacement in high-risk patients. N Engl J Med. 2011;364(23):2187-98.

6. Vahanian A, Alfieri O, Andreotti F, Antunes MJ, Barón-Esquivias G, Baumgartner $\mathrm{H}$, et al. Guidelines on the management of valvular heart disease (version 2012). The Joint Task Force on the Management of Valvular Heart Disease of the European Society of Cardiology (ESC) and the European Association for CardioThoracic Surgery (EACTS). Eur Heart J.2012;33(19):2451-96.

7. Tarasoutchi F, Montera MW, Grinberg M, Barbosa MR, Piñeiro DJ, Sánchez CEM, et al. Diretriz Brasileira de Valvopatias - SBC 2011, Diretriz Interamericana de Valvopatias - SIAC 2011. Arq Bras Cardiol. 2011;97(5 Supl. 1):1-67.

8. Cribier A, Eltchaninoff H, Bash A, Borenstein N, Tron C, Bauer F, et al. Percutaneous transcatheter implantation of an aortic valve prosthesis for calcific aortic stenosis: first human case description. Circulation. 2002;106(24):3006-8.

9. Instituto Brasileiro de Geografia e Estatística (IBGE). Perfil dos Idosos Responsáveis pelos Domicílios no Brasil [Internet]. Rio de Janeiro; 2000 [citado 2013 out. 07]. Disponível em: http:// www.ibge.gov.br/home/estatistica/populacao/perfilidoso/

10. Osnabrugge RL, Mylotte D, Head SJ, Van Mieghem NM, NkomoVT, LeReun CM, et al. Aortic stenosis in the elderly: disease prevalence and number of candidates for transcatheter aortic valve replacement: a meta-analysis and modeling study. J Am Coll Cardiol. 2013; 62(11):1002-12.

11. Toggweiler S, Humphries $\mathrm{KH}$, Lee $\mathrm{M}$, Binder RK, Moss RR, Freeman $\mathrm{M}$, et al. 5-year outcome after transcatheter aortic valve implantation. J Am Coll Cardiol. 2013;61(4):413-9.

12. SOURCE XT One-Year Numbers May Be Best TAVR Survival Data So Far. In: Medscape [Internet] [cited 2013 Oct 07]. Available from: http://www.medscape.com/viewarticle/804576

13. Reynolds MR, Magnuson EA, Wang K, Lei Y, Vilain K, Walczak J, et al.; PARTNER Investigators. Cost-effectiveness of transcatheter aortic valve replacement compared with standard care among inoperable patients with severe aortic stenosis results from the placement of aortic transcatheter valves (PARTNER) trial (Cohort B). Circulation. 2012;125(9):1102-9.

14. Kodali SK, Williams MR, Smith CR, Svensson LG, Webb JG, Makkar RR, et al. Two-year outcomes after transcatheter or surgical aortic-valve replacement. N Engl J Med. 2012;366(18):1686-95

15. Hlatky MA, Mark DB. Economics and cardiovascular disease. In: Braunwald E, Zipes DP, Libby P, editors. Heart disease. Philadelphia: Saunders; 2001. p. 19-26.

16. Mark DB, Hlatky MA. Medical economics and the assessment of value in cardiovascular medicine: Part I. Circulation. 2002; 106(4):516-20.

17. Brecker SJD. Long-term results and cost-effectiveness analysis of ADVANCE trial. In: Presented at EuroPCR 2013 [Internet]. [cited 2013 Sept 22]. Available from: europcr.com

18. Doble B, Blackhouse G, Goeree R, Xie F. Cost-effectiveness of the Edwards SAPIEN transcatheter heart valve compared with standard management and surgical aortic valve replacement in patients with severe symptomatic aortic stenosis: A Canadian perspective Thorac Cardiovasc Surg. 2013;146(1):52-60.

19. Watt M, Mealing S, Eaton J, Piazza N, Moat N, Brasseur P, et al. Cost-effectiveness of transcatheter aortic valve replacement in patients ineligible for conventional aortic valve replacement. Heart. 2012;98(5):370-6.

20. Queiroga MAC, Nishikawa AM, Paladini L, Lemos PA, Brito F, Sarmento-Leite $\mathrm{R}$, et al. Implante por cateter de bioprótese valvar aórtica para o tratamento da estenose valvar aórtica grave em pacientes inoperáveis sob perspectiva da saúde suplementar: análise de custo-efetividade do TAVI. Rev Bras Cardiol Invasiva. 2013;21(3):213-20.

21. Reynolds MR, Magnuson EA, Lei $Y$, Wang K, Vilain K, Li H, et al.; PARTNER Investigators. Cost-effectiveness of transcatheter aortic valve replacement compared with surgical aortic valve replacement in high-risk patients with severe aortic stenosis results of the PARTNER (Placement of Aortic Transcatheter Valves) trial (Cohort A). J Am Coll Cardiol. 2012;60(25):2683-92. 